\title{
Arte, cultura o entretenimiento en el cine: ¿Qué modelo cinematográfico prefieren los espectadores para tomar la decisión de asistir a ver una película? (Arts, culture or entertainment in motion pictures: What film model do spectators prefer on the decision making to watch a movie?)
}

\author{
David Fernando Lozano Treviño` \& María Eloísa Treviño Ayala* \\ Universidad Autónoma de Nuevo León, Facultad de Ciencias Políticas y \\ Administración Pública, San Nicolás de los Garza, N.L., México \\ *Universidad de Monterrey, San Pedro Garza García, N.L., México \\ Email: davidflozano@gmail.com
}

Keywords: arts, consumption, entertainment, film production organizations, LozanoBarragan syndrome

\begin{abstract}
This research paper has as main purpose to determine which film model is more convenient for the Mexican film production organizations in the search of increasing the possibilities of spectators to attend and watch their movies. The character that the films have as popular and academic arts and the elements that compose it is analyzed. We study the way in which motion pictures work as cultural tools. We highlight the importance of movies as an entertainment product and how this aspect impacts in the consumption of movie tickets in the box office. Lozano-Barragan syndrome is detailed and how filmmakers can suffer this artistic, marketing and economic discomfort. Finally, we make some linear regressions to determine the impact that the film models inclusions have on increasing the possibilities of spectators attending to the films.
\end{abstract}

Palabras clave: arte, consumo, entretenimiento, organizaciones de producción cinematográfica, síndrome Lozano-Barragán.

Resumen. Este artículo de investigación tiene como finalidad determinar qué modelo cinematográfico es más conveniente para las Organizaciones de Producción Cinematográficas Mexicanas en la búsqueda de aumentar las posibilidades de que los espectadores asistan a ver sus películas. Se analiza el carácter que el cine tiene como arte 
popular y académico, así como los elementos que lo conforman. Se estudia la manera en que las películas funcionan como herramienta cultural. Se resalta la importancia del cine como producto de entretenimiento y cómo esta cualidad impacta en el consumo de boletos en taquilla. Se detalla el síndrome Lozano-Barragán y cómo los cineastas pueden padecer este malestar artístico, mercadológico y económico. Finalmente, se efectúan regresiones lineales para determinar el impacto que tiene la inclusión de los modelos cinematográficos en el incremento de las posibilidades de asistencia para ver las películas.

\section{Introducción}

Las Organizaciones de Producción Cinematográfica (OPC) tienen dos vertientes importantes en cualquier país: 1) funcionan como motor industrial y de crecimiento económico al llevar productos de interés para los consumidores y 2) son un reflejo artístico y cultural, generalmente del país que produce la película (Gómez, R. 2005). Bajo este punto de vista, podemos deducir que unidos, los negocios y la cultura, lograrán una mejor comercialización de obras cinematográficas al producirlas de forma que busquen satisfacer las necesidades de entretenimiento de los espectadores (Lozano, D. et al 2009); mientras los deseos de los artistas cinematográficos de culturizar o transmitir un sentimiento o idea que impacte en el espectador, también son cumplidos.

Producir películas que entretengan a los clientes sin olvidar su esencia artística que despierta en el público un sentido de reflexión ante la vida y ser una herramienta cultural que educa a los pueblos, son políticas empleadas no sólo por los gobiernos, sino también por numerosas OPC en el mundo que desarrollan las dos vertientes del cine antes mencionadas. De esta manera, las OPC plantean su objetivo de satisfacer a espectadores cada vez más demandantes de productos culturales entretenidos y con contenido.

El cine es un bien que se desplaza a un consumidor o espectador, por lo que debe tener elementos mercadológicos atractivos para este fin, pero a su vez, debe recorrer sendas artísticas y culturales inherentes a las bellas artes y a la cultura. De forma no muy afortunada para la vertiente económica, algunas OPC se han enfocado sólo en producir películas con tintes artísticos, sin lograr considerables recaudaciones en taquilla y con el sólo objetivo de satisfacer las necesidades artísticas del director de una cinta (Lozano, D. et al 2011). Esto a su vez ha provocado que algunos cineastas, cuando se enfrentan al fracaso en taquilla debido al poco interés de la audiencia por ver

\section{F. Lozano \& M. E. Treviño}


sus films, argumenten que los consumidores (espectadores) tienen la culpa de dicho descalabro ya que no pudieron entender la película o no saben de la naturaleza cultural y artística del cine; error de las OPC que caen en el llamado síndrome Lozano-Barragán (SLB) (Lozano, et al 2013). Por otro lado, es conveniente hacer mención del extremo opuesto, donde las películas que sólo buscan entretener, en ocasiones, tienen resultados negativos en taquilla, pues la calidad artística es deficiente y el espectador siente un "hueco" al no haber apreciado algún elemento con contenido en el film, como la dirección, fotografía, historia o las actuaciones; o mostrar algún grado de insatisfacción porque la cinta no le "dejó" algo, es decir, por no aprender.

Ahora, ¿qué desea el espectador realmente cuando asiste a las salas de cine? ¿Apreciar las ideas artísticas del talento, culturizarse o simplemente entretenerse? ¿Qué posibilidades habrá de que un espectador adquiera un boleto en taquilla si la película sólo muestra elementos artístico, culturales 0 de entretenimiento? ¿Se incrementarán o se verán afectadas? El consumidor tomará en cuenta, al momento de comprar un boleto en taquilla, que la película sea importante para él o ella, que tenga un atractivo emocional y que sea de interés (Assael, H. 1999). Así, las películas deberán contener elementos de las vertientes antes mencionadas, pero el ordenamiento y la cantidad de éstas permitirá identificar la que mayor impacto tendrá en los ingresos en taquilla y que, por supuesto, cualquiera OPC requerirá para su supervivencia en el mercado.

En el caso de México, el cine cuenta con épocas interesantes en cuanto a la generación económica y cultural, no sólo para el país sino también para otras naciones. En los años 40, la producción mexicana llegó a colocarse como el cuarto generador de ingresos para el país dentro del PIB (González, D. 2008). La tarea desempeñada por las OPC mexicanas fue la de crear producciones que buscaban satisfacer a un mercado mundial necesitado de entretenimiento frente a los lamentables acontecimientos bélicos que vivían los habitantes de los países Aliados (Lozano, D. et al. 2013).

En la actualidad, el cine mexicano parece trascender, incluso, las fronteras nacionales. Los directores mexicanos Guillermo del Toro (Titanes del Pacífico, 2013; Hellboy: el ejército dorado, 2008), Alfonso Cuarón (Gravedad, 2013; Hijos del hombre, 2006); los actores Salma Hayek o Diego Luna, o películas mexicanas que han sido bien aceptadas en el extranjero 
como El laberinto del Fauno (2006) o No se aceptan devoluciones (2012) son ejemplos de cineastas o producciones exitosas y con ingresos importantes ya sea por la participación de los artistas mexicanos o por la producción desarrollada. Parte de estas producciones han sido desarrolladas en una de las industrias más grandes en el ámbito cinematográfico: Hollywood.

Para seguir creciendo, las OPC mexicanas deben trabajar en fórmulas cinematográficas y de negocios que permitan la creación de películas nuevas que sean atractivas para los espectadores en pantallas comerciales no sólo nacionales, sino también en el mercado estadounidense, caracterizado por ser el mayor consumidor de filmes, o bien en mercados internacionales que se destaquen por su consumo. Igualmente, las OPC deben centrarse en buscar formas que no disparen los costos de producción ni que estén desfasados de los recursos accedidos en los estímulos gubernamentales sin olvidar, también, el carácter artístico o cultural del cine (Lozano, D. et al 2012).

Determinar qué posibilidades hay de que asistan los espectadores mexicanos según el énfasis que se le da a la película: cultural, artística o de entretenimiento; será importante para las OPC en la búsqueda de garantizar mayores ingresos a sus producciones, sobre todo en México, el área de estudio de esta investigación científica. Entender que el cine debe recorrer la senda de la diversión y al mismo tiempo andar por valles culturales y artístico es inherente a su esencia de producto cultural y es tarea de cualquier productor de cine (Lozano, D. et al. 2013). Será conveniente que los directores eviten caer en el síndrome Lozano-Barragán, al culpar a los espectadores del fracaso en taquilla de sus películas, si estos se centraron únicamente en vías artísticas o culturales sin antes tomar en cuenta las necesidades de la persona más importante del cine: el espectador.

\section{Planteamiento del problema}

El desconocimiento de las preferencias de los espectadores dificulta la obtención del éxito en las OPC. Éxito conceptualizado, en este artículo de investigación, bajo una perspectiva de asistencia a las salas de cine y, por lo tanto, en la venta de boletos en taquilla. La escaza concientización de estudios científicos, por parte de las OPC, dificulta la acertada toma de decisiones que, teniendo los estudios en la mano, ubiquen los deseos de los

\section{F. Lozano \& M. E. Treviño}


espectadores en cuanto a sus necesidades. Con lo anterior, no existirán motivos para caer en el SLB ni escusas para que los productores y directores no seleccionen adecuadamente algún modelo cinematográfico que se enfoque, principalmente, en el entretenimiento, la cultura o la apreciación de ideas artísticas, según lo que el mercado demanda.

\section{Objetivo}

Determinar qué posibilidades hay de incrementar el éxito al priorizar el uso del modelo alternativo (MA), modelo clásico (MC) o modelo clásico hollywoodense $(\mathrm{MCH})$ en las producciones de las OPC mexicanas.

\section{Hipótesis de la investigación}

Las siguientes son las hipótesis que trabajaremos en este estudio:

$\mathrm{H} 1$ : Las OPC mexicanas que dan prioridad al entretenimiento, usando el $\mathrm{MCH}$, incrementan sus posibilidades de que los espectadores en México asistan a ver sus películas.

H2: Las OPC mexicanas que dan prioridad a la cultura, usando el MC, incrementan sus posibilidades de que los espectadores en México asistan a ver sus películas.

H3: Las OPC mexicanas que dan prioridad al arte, usando el MA, incrementan sus posibilidades de que los espectadores en México asistan a ver sus películas.

\section{El cine como obra de arte}

El arte es una manifestación humana que expresa una visión personal y desinteresada que interpreta lo real o lo imaginado con recursos plásticos, lingüísticos, visuales o sonoros. El arte canaliza las expresiones sensibles del ser para que lleguen a otros, e incluso que trasciendan el espacio y el tiempo. Para Platón, los sentimientos se plasman mediante formas, sonidos, imágenes 0 letras que las personas interpretan cognitivamente, para transformar ese significado en algo sensitivo.

En un amplio sentido académico, definimos al arte como un conjunto de preceptos y reglas necesarios para hacer bien cualquier cosa (Flores, A. et al. 2009). Entonces, pudiéramos incluir la gastronomía, los deportes y 
muchas actividades bien desarrolladas. Más aún, cuando hacemos referencia al cine, nos referimos a las bellas artes, las cuales tienen como finalidad la expresión de la belleza, cualidad sobresaliente en la arquitectura, escultura, pintura, música, literatura, teatro y, a nuestro objeto de estudio, el cine.

Platón no llegó a establecer bien a bien el concepto de belleza. Reflexionó que era más que la apariencia física y se preguntó si lo bello era la causa del bien o si solamente se atribuía a los placeres de la vista y el oído. Lo único que concluyó es que las cosas bellas son difíciles de alcanzar. Con este argumento, podemos referir, al cine, comprendido en las artes audiovisuales, como un arte que requiere de la vista y del oído para su disfrute (Flores, A. et al. 2009).

Aristóteles consideraba el orden y la exactitud como componentes que definen la belleza. San Agustín dijo que la belleza consiste en la unidad y orden que surgen de la complejidad. Este orden comprendería el ritmo, la simetría o las proporciones. Tomás de Aquino tuvo un concepto más amplio, pues además de incluir la armonía y la calidad o brillantez, consideraba la integridad. Finalmente, Epicuro proponía que la belleza es todo aquello que nos llena de placer.

Por lo tanto, el cine, como el arte de contar historias por medio de imágenes y sonido, se vuelve una obra cuando se impregna de belleza, es decir, cuando ordena o armoniza el caos, infundiendo en los espectadores deleite espiritual. Esta propiedad se da en la naturaleza y, como significación sensible, en las obras cinematográficas. Al visualizar el cine como obra artística, encontramos en él la actividad y el producto mediante el cual el ser humano expresa ideas, emociones 0 , en general, una visión del mundo, a través de diversos recursos. El cine como arte expresa percepciones y sensaciones que tienen los seres humanos que no son explicables más que de este modo (Lozano, D. et al 2013).

Ricciotto Canudo teórico del cine, fue el primero en clasificarlo como séptimo arte y como tal puede ser visto de dos maneras:

a. Popular.- Se da cuando la sociedad, como pueblo, la genera en respuesta a sus necesidades. Se aprende de manera empírica y suele ser muy práctica y funcional. Este tipo de películas preservan técnicas aprendidas en talleres de producción y refleja costumbres y tradiciones mediante las imágenes apreciadas y los sonidos percibidos. 
b. Académico.- Se aprende en las escuelas. Dichas películas siguen las reglas estéticas y las teorías establecidas. Se fundamentan en las experiencias personales de los artistas (directores principalmente) quienes buscan el reconocimiento; se valora más en él o ella, la diferencia que la semejanza. Particularmente, este tipo de películas van encaminadas a transmitir ideas y sentimientos del director como artista principal, sin tomar tanto en cuenta los deseos y necesidades de los espectadores como consumidores de un producto cinematográfico.

Ahora, cuando los espectadores se encuentran con películas impregnadas de elementos artísticos, deberán contar con conocimientos previos que les permitan observar, estudiar e investigar las imágenes y sonidos comprendidos en los filmes. Los componentes de cualquier obra cinematográfica son:

1. Tema.- Se refiere al significado, a la explicación por la experiencia de lo que se puede ver, oír, sentir y pensar. Pobreza, guerra, esperanza, son algunos ejemplos.

2. Concreto o abstracto.- Lo primero describe todo aquello en lo que todos podemos estar de acuerdo en cuanto a su figura o significado. Lo abstracto será aquello que pierde su referencia con lo convencional, es algo que no deja claro en el espectador su significado.

3. Signo.- Es la cosa representada tal cual. Por ejemplo, si un actor toma una manzana y la muerde, simplemente se alimenta de este fruto.

4. Símbolo.- Aquí se le confiere otro significado a lo que se aprecia. En el caso anterior, el actor hará referencia a la sensualidad o el pecado.

5. Composición.- Es propiamente el orden que se les da a las cosas teniendo como incentivo principal que el artista comparta su significado consigo mismo o con los espectadores.

A pesar que en las creaciones cinematográficas se ocupan de la narrativa, edición y guión, es el director el verdadero artista el cual propone y conjuga todos los conceptos antes mencionados. En la práctica se vuelve muy difícil delimitar la calidad artística de una película. Más, el cine se vuelve una obra que busca la belleza y transmitir ideas del director a un público expectante, el cual, deberá contar con preparación previa, ya sea por lo que ha vivido, estudiado o experimentado, para poder apreciar dicho producto artístico. 
Finalmente, el arte ha influido mucho en el desarrollo no sólo nacional, sino también mundial. Grandes obras de la literatura inglesa, esculturas y arquitecturas italianas y obras cinematográficas son ahora un patrimonio mundial. Junto con la parte artística, la actividad económica se ha visto impulsada gracias a esta contribución que las artes han hecho para sus países.

\section{El cine como herramienta cultural}

La cultura, se enfoca en los valores que uno aprende hasta la edad de alrededor 10 años, es decir, prácticamente los criterios centrales aprendidos en la casa por la familia. Aparte de la sección central, también existe la sección superficial que se aboca en conocer las costumbres, símbolos y héroes los cuales se aprenden en la escuela de la vida (Badii, M. et al. 2004). Se refiere como criterios centrales a todas aquellas características intelectuales y conductuales que distinguen e identifican a un ser humano, y que fueron aprendidas en la casa, dentro del núcleo familiar. En cuanto a la sección superficial pudiéramos resaltar lo aprendido en la escuela, iglesia 0 cualquier círculo social que nos diferencia de forma individual, pero también de algún otro círculo social.

El cine en particular, juega un papel importante en la trasmisión de criterios culturales pues lo aprendido impacta tanto en nuestros aprendizajes como en la forma de conducta que pudiéramos desarrollar; igualmente, podemos aprender de otras culturas, para así incrementar nuestros conocimientos. Por ejemplo, tomemos los sentimientos procomunistas que numerosos jóvenes mexicanos defendieron en los años 60; diez años después muchos de ellos, ya adultos, prefirieron sistemas como el capitalismo o socialismo, en los que el poder reside en los mercados o en la sociedad, respectivamente, más que en el Estado. Películas procomunistas 0 bien anticomunistas, impactaron de alguna forma en la manera de actuar de dichos jóvenes (o posteriormente adultos) mexicanos. Por otro lado, lo aprendido en la casa es más difícil de cambiar, como sentimientos 0 creencias profundamente arraigadas en los padres y transmitidas a los hijos: ser conservador, liberal, el respeto a los adultos mayores, el patriarcado 0 matriarcado, entre otros. 
La cultura también puede ser entendida como todas las formas y expresiones de una sociedad determinada, como lo son las costumbres, prácticas, códigos, género, normas y reglas de la manera de ser, vestimenta, religión, rituales, normas de comportamiento y sistemas de creencias. El cine, como una forma de expresión, es en consecuencia cultura. Éste plasma las diversas costumbres y prácticas del lugar en donde se desarrolla la historia y de las personas de quienes se cuentan estas mismas historias. Refleja diversos códigos y reglas de la manera de ser de las regiones. Se adapta a las vestimentas de los lugares de orígenes de los personajes, sus religiones y las formas de vivir y practicar éstas. Proyecta las normas de comportamiento de las comunidades así como también sus sistemas de creencias sociales (Lozano, D. et al 2013).

La cultura es inherente al desarrollo de conocimiento y las facultades intelectuales del hombre, de cualquier tiempo o lugar, y las características que como grupo y como fenómeno histórico-social lo definen y lo determinan (Flores, A. et al 2009). Desde otro punto de vista, se puede decir que la cultura es toda la información y habilidades que posee un ser humano. El concepto es fundamental para las disciplinas que se encargan del estudio de la sociedad, en especial para la antropología y sociología.

La UNESCO en 1982, declaró: "...que la cultura da al hombre la capacidad de reflexionar sobre sí mismo. Es ella la que hace de nosotros seres específicamente humanos, racionales, críticos y éticamente comprometidos. A través de ella discernimos los valores y efectuamos opciones. A través de ella el hombre se expresa, toma conciencia de sí mismo, se reconoce como proyecto inacabado, pone en cuestión sus propias realizaciones, busca incansablemente nuevas significaciones, y crea obras que lo trascienden" (UNESCO, 1982: Declaración de México). Existen dos tipos de cultura:

a. Cultura popular.- Es una práctica social manejada y expresada por la mayoría del pueblo. En un ámbito cinematográfico comprende acciones como presentar cortometrajes en el cine de la localidad; proyectar en los festivales estatales 0 nacionales documentales o largometrajes elaborados por estudiantes o cineastas amateurs con temáticas nacionales o problemas sociales. 
b. Cultura alta.- Son prácticas sociales diferentes y tienen un grado de dificultad mayor. Comprende la filmación de películas con producción, dirección o historias dignas para representar a México en festivales internacionales, donde pudieran ganar algún premio.

La situación cultural del cine es un objetivo apto para el estudio de las leyes del pensamiento y la acción del hombre (Taylor, E. 1995). El cine en esencia, más allá del primer sentimiento que captemos de carácter comercial, busca hacer reflexionar a la audiencia sobre sí mismo y sobre la sociedad en general. Su carácter racional desde la elaboración del guión hasta el montaje mismo le da un elemento cultural. Algunas películas reflejan una crítica constructiva la cual se muestra de forma ética. A través del cine el hombre ha logrado trascender desde que fue creado por los hermanos Lumière. El carácter cultural del cine se da en tres dimensiones:

1. Físico.- Se revela la relación funcional que se da entre las acciones y los objetos reflejados y los actores. Considera cómo el film muestra los elementos físicos del lugar donde suceden los acontecimientos: el sitio, el clima, los objetos con los que interactúan los personajes, etcétera.

2. Histórico.- Se revela la relación que se da entre los personajes y las fuerzas socioculturales plasmadas en la película, es decir, como queda determinada por el trasfondo cultural de los personajes en cuanto a la educación, religión, costumbres, economía o gustos.

3. Sicológico.- Se revela la identidad transferida por el director, productor, actores o demás miembros del equipo de filmación a la película y que queda evidente a través de la historia, fotografía, actuación, edición, sonido o cualquier otro elemento comprendido en la producción cinematográfica.

La industria cultural crea productos que son más o menos simbólicos, fruto de la creatividad humana y patrimonio cultural de una sociedad al englobar su identidad. En este tipo de productos es imposible disociar valor económico de valor cultural y cada vez se vuelve más difícil mantener los históricos límites entre ambos valores (Arrese, Á. 2004). Dicha industria está y seguirá estando conformada por estos dos pilares que tendrán que mezclarse armónicamente para que las organizaciones culturales puedan avanzar satisfactoriamente hacia el éxito. 


\section{El cine como entretenimiento}

El cine forma parte de un mecanismo económico que reúne a los compradores (espectadores) y vendedores (artistas, productores, distribuidores y exhibidores) de un bien o servicio particular (un boleto de entrada en taquilla para ver una película) (McConnell, C. 1997). Los primeros buscan películas que satisfagan sus necesidades, mientras que los segundos crean productos según estos deseos del mercado. El cine se torna potencialmente comercializable cuando satisface las necesidades de ocio de los espectadores, pero específicamente sus deseos de entretenimiento.

En ocasiones, encontramos que las películas sólo buscan cumplir una necesidad cultural 0 artística de los realizadores. En este caso productores y directores, quienes al contar con un ego de artista, olvidan la parte económica comprendida en el cine; y que muchas veces permite llegar como producto de entretenimiento para las masas. Así, muchos espectadores sienten tedio por éste tipo de productos totalmente culturales 0 completamente artísticos mientras que los productores o directores, que sólo tienen la visión artística del cine, argumentan que: ... "la industria cultural sólo brinda entretenimiento bajo un hostil mandato inherente: ¡diviértete!" (Garduño, C. 2001).

Los espectadores no ocultan sus sentimientos con coraza alguna, sino que se abren a las películas de manera que ni siquiera sus amantes conocen, dejándose llevar por la risa, las lágrimas, el terror, la ira, la compasión, la pasión, el amor o el odio (McKee, R. 2011); es decir, buscan satisfacer sus ávidos deseos de entretenimiento y diversión mediante el aprecio de historias cinematográficas.

El cine, como el arte de contar historias por medio de imágenes y sonido, es parte de una de las actividades a la que le dedicamos más tiempo: narrar y escuchar historias. De hecho, lo interesante es por qué dedicamos tanto tiempo a esto. La respuesta es precisamente por nuestros deseos de entretenernos constantemente. Esta actividad es tan importante para el ser humano como pudiera ser trabajar o convivir. Entretenerse, en un contexto cinematográfico, es el ritual de sentarse en la oscuridad, concentrarse en una pantalla para experimentar el significado de un guión y sentir el ascenso de emociones intensas y dejarse llevar hasta la satisfacción última de dichas emociones (McKee, R. 2011). 
Los factores causales de éxito comercial y los demás componentes narrativos deben estar correctamente manejados y acomodados para crear el efecto que se busca y que llenará y generará satisfacción en el público de las salas de cine. Las OPC se enfocarán en buscar al personal adecuado que impregne su sello distintivo dramático, con un adecuado conocimiento de los factores causales de éxito en las producciones cinematográficas. Dicho personal estará capacitado y actualizado y contará con el conocimiento de ideas, sugeridas y proporcionadas por las sensaciones o las reflexiones del equipo, que al tener el poder de repetirlas, compararlas y unirlas, pueda elaborar exitosas historias nuevas y complejas.

Podemos argumentar que son diversos los elementos que utilizan los cineastas para generar entretenimiento entre los espectadores: la fotografía, los efectos visuales, los efectos especiales, la sonorización, la música, entre otros. La realidad, como lo vimos en párrafos anteriores, aunque los directores y productores se valen de dichas herramientas cinematográficas, es la historia, técnicamente el guión, el elemento principal para entretener al público.

Los tres factores narrativos generadores de satisfacción en los espectadores son (Lozano, D. et al 2012):

1. El personaje principal.- Es el que lleva la acción más importante alrededor del cual se construye el relato y de quien, el espectador llega a tener alguna afinidad. Es piedra angular de toda narración. El personaje se construirá según su ambiente, explorará y plasmará sus condiciones internas y externas. Debe ser capaz de crecer, con fuerza de carácter, en torno a la unidad de opuestos (Egri, L. 1960). Es importante para un modelo que tenga como prioridad divertir, pues se convierte en estrategia de marketing y será el que provocará las acciones que generen entretenimiento entre los espectadores. Igualmente, será necesario construir la sicología del personaje, es decir: sus motivaciones y causas y efectos que lo llevan a ser lo que es y por lo cual los espectadores se sentirán identificados con él (Lozano, D. et al 2012).

La historia será porque el personaje quiere algo o carece de algo. Este énfasis en la falta de algo es vital en el diseño del personaje. Para la realización del personaje se deben contar, por lo tanto, su historia como su sicología (Propp, V. 1972). Cabe mencionar que aquello que desea el personaje principal de una película es algo que el grueso de los

\section{F. Lozano \& M. E. Treviño}


espectadores desea a su vez, o bien aquellos problemas que enfrentan, física y sicológicamente. Los personajes que utilizan los cineastas para crear sus obras, deberán ser distintivos de una historia a otra. Sus características y personalidades son factores que determinan el éxito de una narración audiovisual, y que son altamente explotables para retener la atención del espectador. La serie de películas "Duro de Matar" de J. McTiernan, con el actor estadounidense Bruce Willis encarnando al peculiar detective John Mc Claine o en televisión, la serie "Dr. House" estelarizada por Huge Laurie, crearon tanta simpatía y satisfacción en los espectadores, que los personajes son el principal elemento de enganche entre el público, garantizando así el entretenimiento, que a su vez despierta el deseo de consumo y por lo tanto el éxito comercial (Lozano, D. et al., 2012).

2. Antagonista.- El cine de entretenimiento plantea al mal como fuente de fascinación (González, D. 2008). El antagonista se distingue por su capacidad de inyectar miedo y maldad entre los personajes, y muchas veces entre los espectadores. El sólo hecho de estar en contra no es lo suficientemente fuerte para crear un antagonista, éste tiene que actuar contrario al héroe y a los valores que la sociedad dicta (Lozano, D. et al., 2012). El antagonista debe poner barreras que le hagan imposible, o casi imposible, al personaje central, resolver el conflicto. Cabe mencionar que este factor debe tender a reflejar temores que enfrenta la audiencia en su vida cotidiana y que muchas veces no pueden ser superados; pero que gracias a la magia del cine, el espectador, por medio del personaje principal, tiene el carácter necesario para enfrentarlos y vencerlos (Lozano, D. et al., 2013).

3. Tensión.- Es provocada por la acción y el conflicto de la historia. Es propiamente la que genera el entretenimiento y hace a los espectadores estar al "filo de la butaca". Las películas más exitosas son aquellas que están saturadas de acción, por lo que ésta debe ser incluida al máximo desde la elaboración del guión (Gutiérrez, L. 1978). La acción es una especie de actividad, una forma de movimiento en general. En el momento de estructurar la acción se deben tomar en cuenta diversos puntos como: incrementar la carga emocional al máximo subrayando principalmente el miedo, el valor, la ira, la esperanza, entre otros; el 
tiempo y el ritmo también son importantes pues en cada momento debe pasar algo interesante; y que incremente la carga emocional antes mencionada. El ritmo debe ser ágil y dinámico.

Otro pilar de la estructura de la tensión es el conflicto, es decir, el modo de ser de la acción en el drama y por lo tanto, su presencia es obligatoria. Donde hay un conflicto central, se pueden manejar varios subconflictos. Dentro del manejo de conflicto, los realizadores establecerán los puntos cruciales que serán los motores de la generación de tensión. Su correcto acomodo determinará y permitirá el aumento de la misma, lo que provocará mantener la atención del espectador a lo largo de la película y que a su vez generará una divertida satisfacción.

Los productores que se orientan al cine de entretenimiento, toman en cuenta lo que el espectador desea ver en taquilla más que los propios deseos de los artistas realizadores o en el carácter cultural que el cine representa. Por ejemplo, según el Instituto Mexicano de Cinematografía (IMCINE), en su anuario estadístico de cine mexicano 2012, ubica que el género más demandado en el país fue la acción y aventura con más de 83.2 millones de boletos vendidos representando el $36 \%$ del total de asistencias en el país. En segundo lugar se ubica la animación, con 52.43 millones de asistencias captando el $23 \%$ de las ventas totales (Figura 1).

Figura 1. Millones de boletos vendidos según los géneros de películas. Información relevante para los productores que toman en cuenta los deseos de los espectadores que buscan principalmente entretenerse



${ }^{*}$ Con información del Instituto Mexicano de Cinematografía 
Dichos datos serán tomados en cuenta por los productores para así levantar proyectos que garanticen más certeramente la satisfacción de los espectadores según las demandas de géneros que tiene el mercado.

\section{Características de los cineastas que caen en el síndrome Lozano- Barragán}

Las OPC seleccionan alguno de los tres modelos narrativos en la búsqueda de la satisfacción de los gustos y preferencias de los espectadores como clientes de un producto:

1. Modelo alternativo (MA).- En él, el director desea plasmar sus pensamientos y sentimientos de una forma en que él o ella los pueda entender dejando que el espectador encuentre el significado de la película o que incluso quede sin comprender claramente qué fue lo que pasó durante el film (Lozano, D. et al 2013).

2. Modelo clásico (MC).- El director del film cuenta una historia sobre personajes que desarrollan una acción, sin necesariamente caer en conflictos sicológicos o verse involucrados en disyuntivas al momento de tomar decisiones. La tensión se da en un punto ya hacia el final de la película, sin ser demasiado sustancial. Su orientación va más a resaltar y mostrar las dimensiones de la cultura: el carácter físico dónde suceden las acciones, el pasado histórico que vivieron los personajes y la sicología, es decir la identidad que transfiere el director como artista principal, a la obra, comprendiendo de manera importante sus puntos de vista.

3. Modelo clásico hollywoodense (MCH).-La acción principal saldrá de los personajes individuales como agentes causales y se centra en sus aspectos sicológicos como rasgos del personaje, opciones de acción y decisión, entre otras. El movimiento narrativo empieza cuando el personaje central quiere algo, luego se presenta una fuerza contraria que se opone a que el objetivo se cumpla, misma que es un personaje cuyas metas y características son totalmente opuestas: el antagonista. Lo anterior se encarga de crear conflicto. La tensión, aquí, debe irse acumulando hasta llegar al clímax (Lozano, D. et al 2012). El modelo incluye una cantidad de elementos técnicos como los ángulos de cámara, movimientos de la misma y una configuración visual única (McKee, R. 1997). 
Como ya se mencionó anteriormente, los artistas en ocasiones caen en el error de culpar al espectador del fracaso comercial de la película argumentando que éstos no saben apreciar el arte o no entendieron lo que el director o el productor quisieron decir. A este fenómeno se le acuña síndrome Lozano-Barragán. El director no sólo como artista sino también como empresario debería encontrar la forma de llevar su película a las pantallas, mediante historias que resulten interesantes y contadas de una forma atractiva que no generen insatisfacción, sino que diviertan y entretengan mientras culturizan y hacen reflexionar al espectador (Lozano, D. et al 2011). Igualmente, es importante resaltar que las películas deben satisfacer no sólo una necesidad de entretenimiento entre los espectadores, sino también es un producto que, de forma inherente, tiene el deber de culturizar y hacer reflexionar al público sobre algún tema particular. De lo contrario se generaría un fenómeno hueco, es decir, el espectador quedará con la sensación de que la película no le dejó nada o le faltó algo.

Por otro lado, es importante que los artistas cinematográficos, por medio de las OPC a las que pertenecen, vean que sus películas, al ser productos, son un conjunto de atributos y propiedades capaces de satisfacer de forma ventajosa, sostenida y rentable, las diversas necesidades y deseos de espectadores objetivos (Arrese, Á. 2004) y que para este caso, el producto o película se convierte en una mera promesa para el público que quiere experimentar un momento de diversión o entretenimiento. De cierta manera el espectador compra con su boleto un producto intangible, una promesa de diversión o entretenimiento cualquiera que sea el género de la película, o una promesa artística o cultural, según el modelo que estos prefieran.

Para los espectadores que buscan películas entretenidas, hechas bajo el $\mathrm{MCH}$, se centrarán en personajes atractivos, antagonistas con deseos opuestos al personaje central, el manejo de la tensión, el tema a tratar, el género de la película, etcétera. Los espectadores que prefieren películas producidas dentro del $\mathrm{MC}$ se enfocarán en el aprendizaje que adquieren durante el film; mientras que los que se orientan al MA se sentirán atraídos por la reflexión, la interpretación de símbolos, signos y, en muchos casos, la abstracción.

Para evitar el SLB, las OPC deberán escuchar y atender a los espectadores potenciales, para llevarles películas que deseen ver, mejorando

\section{F. Lozano \& M. E. Treviño}


el atractivo de sus producciones y resolviendo futuros problemas de insatisfacción en el espectador. Lo anterior posiblemente generará mayores ventas en taquilla y disminuirán la publicidad negativa proveniente de boca en boca 0 de la crítica inconveniente que tanto afecta a los ingresos de dichas organizaciones. Además, se podrá canalizar de manera más eficiente la publicidad o cualquier recurso relacionado con la película, igualmente se atenderá el mercado meta de manera específica al tener un amplio conocimiento del cliente.

Algunas OPC consideran que el cine en la actualidad busca únicamente generar una plusvalía económica, es decir una ganancia abstracta obtenida de la diferencia entre el valor social prometido de una obra y su costo de producción. Para ellos, el fin del sistema es su propia reproducción con base en el consumo, únicamente su objetivo de entretenimiento, sin ningún propósito cultural. (Garduño, C. 2010). Las utilidades podrían considerarse por algunos autores como éxito empresarial (Pushpakumar \& Athula Wijewickrama, 2008; Benzing, Manh Chu, \& Kara, 2009; Unger, Keith, Hilling, Gielnik, \& Frese, 2009; Chaganti \& Chaganti, 1983; Paige \& Littrell, 2002).

Sin embargo, no es el único factor que mide una plusvalía económica 0 éxito; las ventas es otro factor determinante en cualquier industria (Che Rose, Naresh, \& Li Yen, 2006; Ali Junejo, Lai Rohra, \& Nawaz Chand, 2009; Arteaga \& Lasio, 2009; Coy, Shipley, Omer, \& Khan, 2007; Alasadi \& Abdelrahim, 2008; Unger, Keith, Hilling, Gielnik, \& Frese, 2009; Hienerth \& Kessler, 2006; Pushpakumar \& Athula Wijewickrama, 2008) y no es la excepción en la industria cinematográfica como productora de bienes que en este caso son culturales.

En la inauguración de la edición 53 de la Muestra Internacional del Cine, en la Cineteca Nacional, El cineasta mexicano Arturo Ripstein, cayó en el SLB al asegurar que el público les da la espalda a los realizadores mexicanos $y$, ante esto, las exhibidoras responden distribuyendo otras películas. Afirmó que no era culpa de los productores y directores, sino del público al que había que prepararlo para apreciar obras cinematográficas.

En gran medida el SLB se da, porque las OPC identifican los errores de otros que les causan daño, en este caso, el fracaso en taquilla. Es una cuestión natural y humana, hasta cierto punto, culpar a los demás. Adjudicar la culpa involucra no sólo determinar lo grave del daño, sino también el 
estado mental de las personas a las que se culpa y el motivo que éstos tienen (Nadler, J. 2012). Lo recomendable sería internalizar la culpa, es decir, identificar perfectamente las necesidades del mercado y con base en eso, no elaborar producciones que no tendrán éxito en taquilla, porque si se filma una película que de antemano la producción sabe que va a fracasar, la culpa siempre será del empresario y deberá responsabilizarse de eso. Por otro lado, no es recomendable subestimar a los espectadores. Su estado mental no está por debajo del de ningún realizador, más bien, tiene deseos, necesidades y preferencias distintas y él o ella saben lo que hacen con su tiempo de ocio y los productos que adquieren durante ese lapso.

Quienes evitan el SLB buscan más bien un equilibrio en la producción cinematográfica. Un ejemplo es el cineasta español Daniel Monzón ganador del premio español Goya a la mejor dirección por la película "Celda 211". Él afirma: "Lo que nunca puedes hacer es culpar al público del fracaso". Además agrega que los miembros de este tipo de OPC deben "quitarse ese halo de soberbia, de petulancia...".

Finalmente, para evitar que las OPC mexicanas padezcan el SLB, se recomienda conocer las posibilidades que tendrán sus películas, hechas bajo el MA, MC, o MCH, de ser vistas por los espectadores en el país. Es decir, si sus películas dan preferencia al arte, a la cultura 0 al entretenimiento, qué posibilidades tendrán de ser apreciadas por los espectadores que a su vez, adquieren un boleto en taquilla, generando así, ventas y una mayor posibilidad de éxito comercial.

\section{Diseño del instrumento}

Se aplicó una encuesta encaminada a determinar si se incrementan las posibilidades de que los espectadores vean una película mexicana al estar filmada bajo el MA, MC o MCH. Es decir, si al considerar las OPC mexicanas transmitir conceptos artísticos, culturizar o entretener, respectivamente, aumentaran las posibilidades de que el público nacional vaya a ver sus producciones.

Las preguntas se respondieron con base en una escala de 1 al 10 , donde 1 es "Nada" y 10 "Totalmente". 
Metodología de la investigación

En la búsqueda de visualizar si las posibilidades de ver una película se incrementan al ser producida en su mayoría bajo el $\mathrm{MA}, \mathrm{MC}, \mathrm{o} \mathrm{MCH}$, se aplicó una encuesta en Monterrey y su área metropolitana. Se considera que los espectadores de dicha región tienen un comportamiento similar a los de Occidente en general y a los de México en particular. Para obtener la muestra se obtuvo la población total del estado de Nuevo León para el 2010 que fue de 4,653,458, según datos del Instituto Nacional de Estadística y Geografía en el país. Igualmente, se basó en datos del mismo instituto que reflejan que el $88 \%$ de los habitantes viven en el área metropolitana seleccionada, es decir, 4, 095,043.

Para obtener respuestas reflexionadas, certeras y lo más precisas posibles, el estudio se realizó con espectadores que ya tuvieran un criterio propio para seleccionar un film al momento de asistir a las salas cinematográficas. Se encuestó sólo a espectadores potenciales mayores de 15 años, los cuales representan el 70.6\%, arrojando una cifra de 2, 891,100.

Así, se procedió a determinar el tamaño de la muestra con un error de estimación (E) del $10 \%$ y un grado de confianza del $95 \%$.

$E($ Error de estimación $)=10 \%$

$p=0.5$

$q=0.5$

$\mathrm{N}($ Población $)=2,891,107$

Con un $95 \%$ de confianza

Obtenemos:

$$
\begin{gathered}
\left(z^{2} p q\right) / E^{2} \\
n=\left(1.96^{2} \times 0.5 \times 0.5\right) \div\left(0.1^{2}\right) \\
n=96
\end{gathered}
$$

Cercano a los 100

Por lo tanto, 100 encuestas fueron las que se contestaron con proporciones similares para hombres, mujeres, edades y estratos socioeconómicos. Las preguntas tomadas en cuenta, de manera específica para este estudio, fueron: 
1) ¿Qué posibilidades hay de que usted vaya a ver una película mexicana que principalmente busque entretenerlo?

2) ¿Qué posibilidades hay de que usted vaya a ver una película mexicana que principalmente busque culturizarlo?

3) ¿Qué posibilidades hay de que usted vaya a ver una película que principalmente busque transmitirle una idea o sentimiento del director como artista principal de la película?

Las variables independientes son:

- Entretener como objetivo principal (X1).- Se da cuando el público apreciará principalmente una película con un personaje central con el que se identifica y que se enfrenta a un antagonista que puede ser el reflejo del entorno del espectador y que con el ingrediente de la tensión, lo mantiene al "filo de la butaca" en todo momento, satisfaciendo así sus necesidades de diversión.

- Culturizar como objetivo principal (X2).- Es cuando la película plasma principalmente formas y expresiones de una sociedad determinada, como lo son las costumbres, prácticas, códigos, género, normas y reglas de la manera de ser, vestimenta, religión, rituales, normas de comportamiento y sistemas de creencias.

- Transmitir una idea o sentimiento del director como objetivo principal (X3).- Se da cuando el director o productor de una película tiene como actividad principal expresar ideas, emociones, o en general, una visión del mundo y no necesariamente toma en cuenta al espectador como consumidor de un bien.

Por otro lado, como variable dependiente tenemos:

- La posibilidad de ver una película $\left(y_{1}\right)$.-Es la aptitud o facultad que tiene un espectador para asistir a ver una película por considerar significativo el modelo mayormente empleado en la producción. Esta misma definición se tomó para " $\mathrm{y}_{2}$ " " $\mathrm{y}_{3}$ ".

Lo siguiente se analizó mediante tres regresiones lineales:

$$
\begin{aligned}
& y_{1}=\beta_{0}+\beta_{1} x_{1}+e \\
& y_{2}=\beta_{0}+\beta_{2} x_{2}+e \\
& y_{3}=\beta_{0}+\beta_{3} x_{3}+e
\end{aligned}
$$


donde:

$\mathrm{X}_{1}=$ Entretener como objetivo principal

$\mathrm{X}_{2}=$ Culturizar como objetivo principal

$\mathrm{X}_{3}=$ Transmitir una idea o sentimiento del director como objetivo principal

$\mathrm{y}_{1}=$ Posibilidad de que el espectador vea una película cuyo objetivo principal es entretener

$\mathrm{y}_{2}=$ Posibilidad de que el espectador vea una película cuyo objetivo principal es culturizar

$\mathrm{y}_{3}=$ Posibilidad de que el espectador vea una película cuyo objetivo principal es transmitir una idea o sentimiento del director como artista principal.

\section{Resultados de la investigación}

Los resultados estadísticos arrojaron la siguiente información, misma que es analizada y discutida a continuación:

La Figura 2 refleja un coeficiente de determinación $R^{2}$ de 0.14 . Este modelo explica el $14 \%$ de la varianza justificada por la variable independiente (cuando la película tiene como objetivo principal entretener) en la dependiente (la posibilidad de que el espectador vea dicho film).

Figura 2. Correlación y regresión entre el entretenimiento como objetivo principal en una película y la posibilidad de ver dicho film por parte del espectador

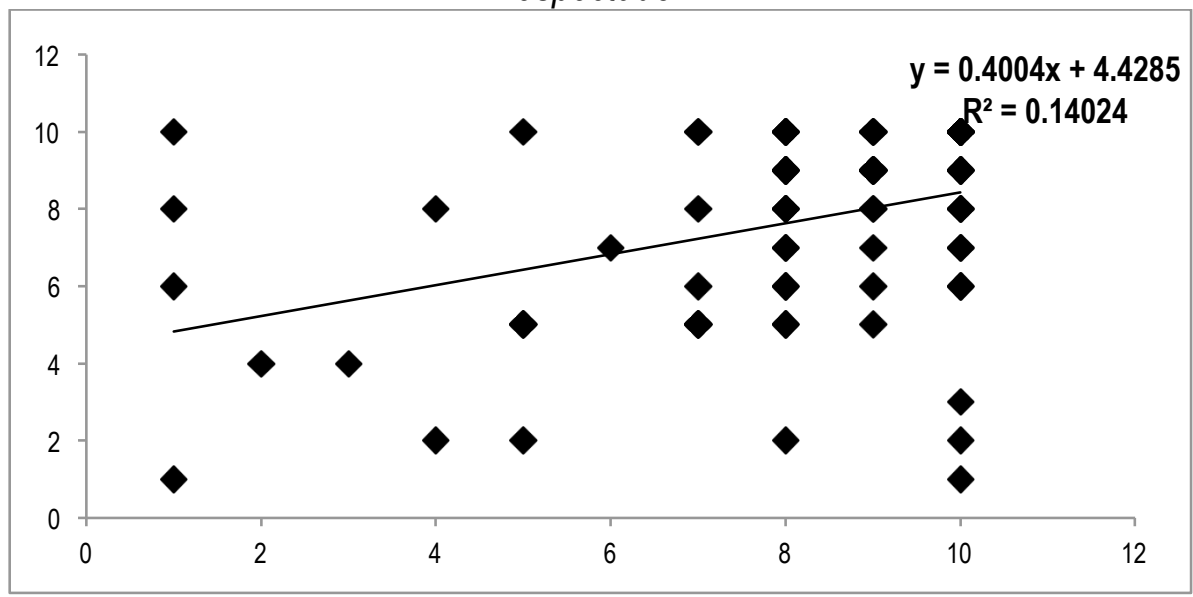


Obteniendo la ecuación de $y=0.4 x+4.428$, observamos que un $14 \%$ del resultado, es decir de la posibilidad de que el espectador vea una película será porque las $\mathrm{OPC}$ incluyeron elementos del $\mathrm{MCH}$ que buscan entretener al público.

Para la Figura 3, donde se muestra la correlación entre culturizar como objetivo principal y la posibilidad de que el espectador vea esta película, obtenemos un coeficiente de determinación de $\mathrm{R}^{2}=0.002$ cifra bastante baja para el modelo. La ecuación es de $y=0.051 x+7.075$. Por lo tanto, la $\mathrm{H} 2$ es rechazada. Evidentemente, las películas hechas bajo el MC son consumidas por algunos espectadores, más son otros factores, y no su elemento cultural, lo que genera las posibilidades para que el espectador tome la decisión de verlas.

Figura 3. Correlación y regresión entre culturizar como objetivo principal en una película y la posibilidad de ver dicho film por parte del espectador

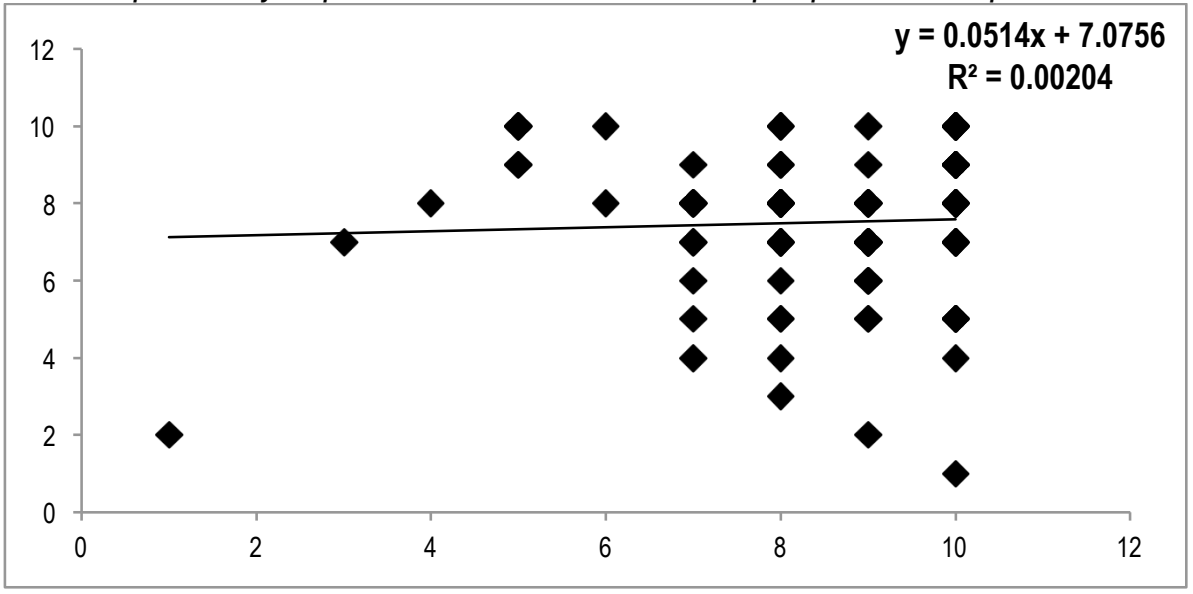

Por último, en la Figura 4 encontramos a las películas que principalmente buscan transmitir ideas o sentimientos del director como artista principal, estas son filmadas en su mayor parte bajo el MA. El modelo explica en un $8.1 \%$ la varianza que en la variable dependiente se da cuando hay un movimiento en la independiente. Con la ecuación de $y=0.293 x+4.54$ establecemos que una OPC busca únicamente transmitir ideas $y$ sentimientos del director como personaje principal, pudiéramos decir, $x=10$, 
la posibilidad de que el espectador vaya a ver la película será de 7.47, Esta parte es la que no sale si sustituyo el 10 en la $x$ de $0.293(10)+4.54$ pero este modelo sólo explica esta cifra en un $8.1 \%$. Por lo que, aunque haya un posible rechazo de esta hipótesis, puede ser un dato a considerar por las OPC mexicanas.

Figura 4. Correlación y regresión entre la transmisión de ideas y sentimientos del director como objetivo principal en una película y la posibilidad de ver dicho film por parte del espectador



\section{Conclusión}

Las OPC desempeñan un papel importante en todas las naciones como fabricantes de bienes culturales. Elaboran productos que serán consumidos y generarán una riqueza económica, pero también sus películas serán vistas durante el tiempo de ocio de las personas, generando entretenimiento, culturización o aprecio de ideas artísticas del director para el público.

El cine, como el arte de contar historias por medio de imágenes y sonido, se ha convertido en una manifestación humana que expresa una visión de un equipo de trabajo en donde el director es el líder de éste. Como obra artística estará impregnada de belleza, definida como ordenar 0 armonizar el caos, deleitando así, a los espectadores como consumidores de 
una obra. Conceptualizado como el séptimo arte, el cine se podrá producir de manera popular 0 académica en donde será esencial que el público conozca e identifique plenamente: 1) el tema tratado en la historia; 2) si la película es concreta, entender lo que se plantea; 3 ) si es abstracta, identificar elementos como el signo o los símbolos y; 4) apreciar la composición plasmada en la fotografía.

En su carácter cultural, el cine busca hacer reflexionar a la audiencia sobre sí mismo y sobre la sociedad. Provocará en el espectador la sensación de haberse "quedado con algo" al momento de ver la película. Este sentimiento se dará mediante la captación de las dimensiones físicas, históricas y sicológicas establecidas y apreciadas en el film.

Circunscripto como un producto de entretenimiento, las OPC buscarán satisfacer los ávidos deseos de diversión de los espectadores, mediante historias cinematográficas. Gracias a las películas, dichas organizaciones, provocarán emociones intensas en el público. Las herramientas narrativas usadas por las OPC cuyo objetivo principal es entretener serán: el personaje principal, el antagonista y la tensión. Estos elementos están comprendidos en los tres modelos estudiados: alternativo, clásico y clásico hollywoodense; pero utilizados de manera distinta en cada uno de ellos caracterizándose el grado de intensidad, sencillez y claridad manifestados en la historia.

El síndrome Lozano- Barragán conceptualiza el padecimiento que sufren algunos artistas cinematográficos, como productores de un bien, que culpan a los consumidores o espectadores que no les gustó la película, del fracaso comercial en taquilla, argumentando que dichos espectadores no supieron entender el producto o que no saben de la naturaleza del mismo. Por otro lado, el fenómeno hueco, se da cuando el espectador se queda con la sensación de que la película "no le dejó algo" o le "faltó algo", refiriéndose que el grado artístico o cultural del cine no fue considerado en lo absoluto por las OPC durante la producción o bien, que no logró ser apreciado por el público. Ambos conceptos deben ser evitados por completo.

En lo que se refiere al trabajo cuantitativo de esta investigación, se encontró que hay un incremento en las posibilidades de que los espectadores asistan a ver una película cuando tiene como objetivo principal entretener; más no es determinante este elemento, pues el público tomará en cuenta algunos otros factores, que no sólo se referirán a las cuestiones narrativas, sino también mercadológicas o de alguna otra índole.

\section{F. Lozano \& M. E. Treviño}


Cuando las OPC consideran la transmisión de ideas artísticas o sentimientos del director al público como objetivo principal, los espectadores manifestarán una leve tendencia a aumentar sus posibilidad de ver el film, pero en una medida menor que si la película da preferencia al entretenimiento. Igualmente, en las películas hechas bajo el MA, otros serán los factores determinantes en la asistencia a las salas de cine. Cabe mencionar, que los resultados para este modelo fueron mejor que para el que tiene como objetivo principal culturizar. La hipótesis referente al MC fue rechazada debido al resultado obtenido. Lo anterior se pudiera dar porque el cine de arte suele tener un nicho del mercado bastante definido, al cual le agrada el aprecio de ideas y sentimientos relacionados con el arte.

\section{Referencias}

Alasadi, R., \& Abdelrahim, A. (2008). Analysis of small business Performance in Syria, Education, Business and Society: Contemporary Middle Eastern Issues, 1(1), 50-62.

Ali Junejo, M., Lai Rohra, C., \& Nawaz Chand, M. (2009). Entreprenuer human capital and growth of small-scale industry. A case study of Sakkur Estate Area of Sindh Pakistan, Australian Journal of Basic and Applied Sciences, 3(3), 2389-2396.

Aristóteles (2004). Metafísica. México, D. F: Grupo Editorial Porrúa.

Arrese, Á. (2004) Algunas consideraciones sobre la gestión de productos y contenidos de los medios, Comunicación y Sociedad, 15(2): 9-44.

Arteaga, M. I., \& Lasio, V. (2009). Empresas dinámicas en Ecuuador: Factores de éxito y competencias de sus fundadores. Academia, Revista Latinoamericana de Administración, 42, 1-19.

Assael, H. (1999). Comportamiento del consumidor. México:, D. F: Internacional Thomas Editores.

Badii, M., A. Pazhkh, J. Abreu \& R. Foroughbakhch (2004). Fundamentos del método científico, Innovaciones de Negocios, 1(1), 89-107.

Benzing, C., Manh Chu, H., \& Kara, O. (2009). Entrepreneurs in Turkey: A factor analysis of motivations, success factors, and problems, Journal of Small Business Management, 47(1), 58-91.

Chaganti, R., \& Chaganti, R. (1983). A profile of profitable and not-so-profitable small business, Journal of Small Business Management, 21(3), 43-51.

Che Rose, R., Naresh, K., \& Li Yen, L. (2006). Entreprenuers success factors and escalation of small and medium-sized enterprises in Malasya, Malasya Journal of Social Sciences, 2(3), 74-80.

Coy, S. P., Shipley, M. F., Omer, K., \& Khan, R. N. (2007). Factors contributory to success: A study of Pakistan's small business owners, Journal of Developmental Entrepreneruship, 12(2), 181-198.

Egri, L. (1960). The art of dramatic writing. Nueva York: Simon and Scuster. 
Flores, A., M. Gómez \& B. Sierra (2009). Apreciación a lo artístico: lo visual y auditivo en la cotidianidad urbana. México: Grupo Editorial Patria.

Garduño, C. (2001). Producción y consumo: Arte y mecánica desde Benjamín y Adorno, Intersticios, 32(15): 41-56.

Gómez, F. (2006). Narrativa cinematográfica y enseñanza del cine, Revisa Científica de Comunicación y Educación, 15(29), 75 - 80.

González, D. (2008). Hollywood: la genealogía secreta. México, D. F: Universidad Autónoma de Nuevo León.

Gutiérrez, L. (1978). Narrativa Filmica. Madrid. Pirámide.

Hienerth, C., \& Kessler, A. (2006). Measuring success in family business: The concept of configurational fit, Family Business Review, 19(2), 115-134.

Lozano, D. (2013). Modelo de internacionalización aplicable a la producción cinematográfica comercial mexicana. Múnich: Editorial GRIN.

Lozano, D., J. Barragán \& E. Treviño (2013). Necesidades de entretenimiento de los espectadores: Cómo evitar que los cineastas mexicanos caigan en el síndrome Lozano-Barragán, Daena: International Journal of Good Conscience, 8(3), 126-156.

Lozano, D., J. Barragán, S. Guerra \& E. Treviño (2011). Superando el Síndrome LozanoBarragán en las organizaciones de producción cinematográfica mexicanas, Daena: International Journal of Good Conscience, 6(2), 1-16.

Lozano, D., J. Barragán \& S. Guerra. (2009). El cine: El negocio de la cultura. UANL, Innovaciones de Negocios, 6(2): 207- 224.

Lozano, D., J. Barragán, S. Guerra \& J. Zúñiga. (2010). Estrategias para el desarrollo cinematográfico comercial mexicano hacia los Estados Unidos, Innovaciones de Negocios, 7(1), 89-104.

Lozano, D., J. Barragán, S. Guerra \& P. Villalpando. (2010). Factores mercadológicos utilizados por las organizaciones de producción cinematográfica (OPC) y su impacto en las ingresos en taquilla, Innovaciones de Negocios, 7(2), 89-104.

Lozano, D., J. Barragán, S. Guerra, E. Treviño \& P Villalpando. (2012). Factores narrativos utilizados por las organizaciones de producción cinematográfica y su impacto en los ingresos en taquilla, Innovaciones de Negocios, 9(18), 279-317.

Lozano, D., J. Barragán, S. Guerra \& P. Villalpando. (2010). Retos del cine mexicano para su consumo en los Estados Unidos, Innovaciones de Negocios, 7(2), 89-104.

McConnell, C. (1997). Economía, principios, problemas y politicas. Bogotá: McGraw Hill Interamericana.

McKee, R. (2011). El guión. Madrid: Albaminus.

Nadler, J. (2012). Blaming as a social process: the influence of character and moral emotion on blasé, Law \& Contemporary Problems, 75(1), 1-31.

Paige, R., \& Littrell, M. (2002). Craft retailers' criteria for success and asociated business strategies, Journal of Small Business Management, 40(4), 314-331.

Platón (2009). Diálogos. México, D. F: Editorial Porrúa.

Propp, V. (1972). Morfología del cuento, Buenos Aires: Juan Goyanarte Editor. 
Pushpakumar, M. D., \& Athula Wijewickrama, A. K. (2008). Planning and performance of SME organizations: Evidence from Japan, International Conference on Business and Management Education, Bangkok, Thailand.

San Agustín (2005). Confesiones. México, D. F. Editorial Porrúa.

Tylor, B. (1995). La ciencia de la cultura. Madrid: Cátedra.

Tomás de Aquino. (2007). Suma contra los gentiles. México, D. F: Editorial Porrúa.

Unger, J. M., Keith, N., Hilling, C., Gielnik, M. M., \& Frese, M. (2009). Deliberate practice among South African small business, Journal of Occupational and Organizational Psychology, 82(1), 21-44. 